\title{
Rapid expansion of TILs from patients with glioma and recognition of autologous tumor
}

\author{
Liu Zhenjiang ${ }^{1}$, Qingda Meng ${ }^{1}$, Oscar Persson ${ }^{1}$, Bartek Jiri ${ }^{1}$, Thomas Poiret ${ }^{1}$, Lalit Rane ${ }^{1}$, Elena B Rangelova², \\ Ernest Dodoo ${ }^{3}$, Markus Maeurer $^{1 *}$ \\ From Society for Immunotherapy of Cancer 29th Annual Meeting \\ National Harbor, MD, USA. 6-9 November 2014
}

\section{Background}

Tumor-infiltrating $\mathrm{T}$ cells (TIL) may represent a viable source of $\mathrm{T}$ cells for the biological treatment of patients with tumors of the central nervous system. We established a rapid TIL expansion protocol for patients with glioblastoma, and tested the recognition of short-term expanded tumor autologous tumor cell lines defined by cytokine production from responding $\mathrm{T}$ cells.

\section{Material and methods}

Glioma tumor tissue was obtained from 15 patients with glioblastoma, tumor cell lines were established and TIL could be successfully expanded in $15 / 15$ cases using a cytokine cocktail IL-2/IL-15/IL-21, OKT-3 and irradiated, allogeneic feeder cells. Intracellular Cytokine Staining (ICS) was used to detect antigen-specific immune responses. Autologous tumor cells or TAAs (NY-ESO-1, Survivin and EGFRvIII peptides) were cocultured with TILs for 6 hours in the presence of Brefeldin A as well as in medium (negative control), or PMA +Ionomycin (positive control). CD3, CD4 and CD8 markers were combined with either IL-2, IL17, TNFalpha, IFNgamma production or 41-BB expression. VB family composition, exhaustion/activation as well as differentiation markers were tested by flow cytometry.

\section{Results}

15/15 TIL could be successfully expanded (up to $10 \mathrm{e} 10$ cells) using IL-2, IL-15 and IL-21. The majority of TIL exhibited a mixture of $\mathrm{CD} 4+, \mathrm{CD} 8+$, as well as CD3+ (TCRalpha/beta) CD4-CD8- T cells with an CD45RACCR7+ phenotype. TILs showed low frequencies of exhaustion markers, i.e. PD-1 (in CD8+ TILs: median:

${ }^{1}$ Karolinska Insitutet, Stockholm, Sweden

Full list of author information is available at the end of the article
3.03\%, mean: $3.40 \%$, in CD4+ TILs: median: $2.10 \%$, mean: $7.73 \%$ ), TIM-3 (in CD8+ TILs: median: 0.30\%, mean: $1.21 \%$, in CD4+ TILs: median: $0.70 \%$, mean: $1.00 \%$ ), CTLA-4 (in CD8+ TILs: median: $1.47 \%$, mean: $1.73 \%$, in CD4+ TILs: median: $0.04 \%$, mean: $0.07 \%$ ) and LAG-3 (in CD8+ TILs: median: $8.87 \%$, mean: $30.00 \%$, in CD4+ TILs: median: $1.21 \%$, mean: $1.25 \%)$. Some TIL cultures exhibited preferential usage of VB families (i.e up to $60 \%$ VB22 or VB1 in CD4+ or CD8+ TIL). TIL from individual patients exhibited NY-ESO-1 specificity up to $2 \%$ in CD4 and CD8+ T cells, yet up to $25 \%$ IFN and TNF production directed against autologous tumor cells, defined by ICS. Whole genome sequencing is currently performed in gliomas to subsequently test for subsequent TIL recognition.

\section{Conclusion}

TIL from glioma samples can be reliably and successfully expanded in IL-2/IL-15 and IL-21, they exhibit a Th1-cytokine production pattern and recognize autologous tumor cells ex vivo. Glioma - reactive TIL represent a viable source the cellular therapy for patients with glioblastoma and a Phase I safety trial is currently prepared at Karolinska.

\section{Consent}

Written informed consent was obtained from the patient for publication of this abstract and any accompanying images. A copy of the written consent is available for review by the Editor of this journal.

\section{Authors' details}

${ }^{1}$ Karolinska Insitutet, Stockholm, Sweden. ${ }^{2}$ Karolinska Insitutet, Karolinska University Hospital, Stockholm, Sweden. ${ }^{3}$ Dept. of Neurosurgery, Karolinska University Hospital, Stockholm, Sweden.
() Biomed Central 
doi:10.1186/2051-1426-2-S3-P27

Cite this article as: Zhenjiang et al:: Rapid expansion of TILs from

patients with glioma and recognition of autologous tumor. Journal for

ImmunoTherapy of Cancer 2014 2(Suppl 3):P27.

Submit your next manuscript to BioMed Central and take full advantage of:

- Convenient online submission

- Thorough peer review

- No space constraints or color figure charges

- Immediate publication on acceptance

- Inclusion in PubMed, CAS, Scopus and Google Scholar

- Research which is freely available for redistribution

Submit your manuscript at 